\title{
Health risks posed to infants in rural China by exposure to short- and medium-chain chlorinated paraffins in breast milk
}

\author{
Dan Xia ${ }^{\mathrm{a}, \mathrm{b}}$, Li-Rong Gao ${ }^{\mathrm{a}, *}$, Ming-Hui Zheng ${ }^{\mathrm{a}}$, Jing-Guang Li $^{\mathrm{c}}$, Lei Zhang ${ }^{\mathrm{c}}$, Yong-Ning Wu ${ }^{\mathrm{c}, *}$, Lin Qiao ${ }^{\mathrm{a}, \mathrm{b}}$, \\ Qi-Chang Tian ${ }^{\text {a }}$, Hui-Ting Huang ${ }^{\text {a,b }}$, Wen-Bin Liu ${ }^{a}$, Gui-Jin Su ${ }^{a}$, Guo-Rui Liu ${ }^{\text {a }}$ \\ a State Key Laboratory of Environmental Chemistry and Ecotoxicology, Research Center for Eco-Environmental Sciences, Chinese Academy of Sciences, Beijing 100085, China \\ b University of Chinese Academy of Sciences, Beijing 100085, China

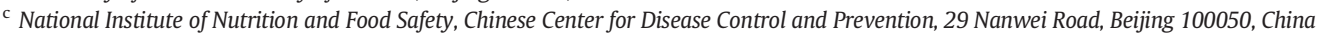

\section{A R T I C L E I N F O}

\section{Article history:}

Received 30 December 2016

Received in revised form 16 March 2017

Accepted 17 March 2017

Available online 26 March 2017

\section{Keywords:}

SCCPs

MCCPS

Human breast milk

Infants' health risk

China

\begin{abstract}
A B S T R A C T
Chlorinated paraffins (CPs) are complex mixtures of synthetic chemicals found widely in environmental matrices. Short-chain CPs (SCCPs) are candidate persistent organic pollutants under the Stockholm Convention. There should be great concern about human exposure to SCCPs. Data on CP concentrations in human breast milk is scarce. This is the first study in which background SCCP and medium-chain CP (MCCP) body burdens in the general rural population of China have been estimated and health risks posed to nursing infants by CPs in breast milk assessed. The concentrations of 48 SCCP and MCCP formula congeners were determined in 24 pooled human milk samples produced from 1412 individual samples from eight provinces in 2007 and 16 provinces in 2011. The samples were analyzed by comprehensive two-dimensional gas chromatography electron capture negative ionization high-resolution time-of-flight mass spectrometry. The median SCCP and MCCP concentrations were 303 and $35.7 \mathrm{ng} \mathrm{g}^{-1}$ lipid weight, respectively, for the 2007 samples and 360 and $45.4 \mathrm{ng} \mathrm{g}^{-1}$ lipid $^{-}$ weight, respectively, for the 2011 samples. The $\mathrm{C}_{10}$ and $\mathrm{C}_{14}$ homologs were the dominant CP carbon-chain-length groups, contributing $51 \%$ and $82 \%$ of the total SCCP and MCCP concentrations, respectively. There are probably multiple CP sources to the general Chinese population and numerous exposure pathways. The median estimated daily SCCP and MCCP intakes for nursing infants were 1310 and $152 \mathrm{ng} \mathrm{kg}^{-1} \mathrm{~d}^{-1}$, respectively, in 2007 and 1520 and $212 \mathrm{ng} \mathrm{kg}^{-1} \mathrm{~d}^{-1}$, respectively, in 2011. SCCPs do not currently pose significant risks to infants in China. However, it is necessary to continuously monitor $\mathrm{CP}$ concentrations and health risks because $\mathrm{CP}$ concentrations in Chinese human breast milk are increasing.
\end{abstract}

(C) 2017 Elsevier Ltd. All rights reserved.

\section{Introduction}

Chlorinated paraffins (CPs) are high-production-volume synthetic chemicals that have been widely used as metal-working fluids and flame retardants for plastics (Sverko et al., 2012). Commercial CPs are classified, according to their carbon chain lengths, as short chain CPs (SCCPs; with carbon chain lengths of $\mathrm{C}_{10-13}$ ), medium chain CPs (MCCPs; with carbon chain lengths of $\mathrm{C}_{14-17}$ ), and long chain CPs (with carbon chain lengths of $\mathrm{C}_{18-30}$ ), and the degree of chlorination of each class of CP ranges from $30 \%$ to $70 \%$ (Tomy et al., 1998). SCCPs and MCCPs are persistent and can bioaccumulate, so there is concern about the potential adverse effects of SCCPs and MCCPs on human health (Bayen et al., 2006; Houde et al., 2008; Li et al., 2016). SCCPs at high concentrations have been found to be hepatotoxic in trout and

\footnotetext{
* Corresponding authors.

E-mail addresses: gaolr@rcees.ac.cn (L.-R. Gao), wuyongning@cfsa.net.cn (Y.-N. Wu).
}

rats (Cooley et al., 2001). SCCPs have also been found to be carcinogenic in rats and mice (ECB, 2000). SCCPs have therefore been classed as candidate persistent organic pollutants under the Stockholm Convention (Persistent Organic Pollutants Review Committee, 2009).

Production of CPs started in the 1930s, and it has been estimated that 7.5-11.3 kt of CPs were produced in Canada, Europe, and the USA in 2007 and that about $600 \mathrm{kt}$ of CPs were produced in China in 2007 (van Mourik et al., 2015; Wei et al., 2016). The production and use of CPs is currently not restricted in China, and annual CP production is continually growing. The rapid increase in the amounts of CPs produced and the wide use of CPs in China have led to CPs being ubiquitous in the Chinese environment. Relatively high SCCP concentrations (1000$3500 \mathrm{ng} \mathrm{g}^{-1}$ dry weight (dw)) have been found in fish samples from a lake that receives sewage treatment plant effluent in Beijing, China, and such concentrations could pose risks to humans and other organisms (Zeng et al., 2011). Extremely high CP concentrations have been found in wild animal tissues from the Yangtze River Delta (8000- 
$340,000 \mathrm{ng} \mathrm{g}^{-1}$ lipid weight (lw)) (Zhou et al., 2016) and in terrestrial bird tissues from the Pearl River Delta (620-17,000 $\mathrm{ng} \mathrm{g}^{-1} \mathrm{lw}$ ) (Luo et al., 2015). There should be great concern about the exposure of Chinese people to CPs because of the potential for CPs to bioaccumulate and biomagnify.

There is concern about the presence of environmental pollutants in human breast milk because the pollutants could negatively affect the health of breastfeeding infants. A fetus will be exposed to potentially harmful chemicals transferred through the placenta, but breast milk is the main route through which infants are exposed to potentially harmful chemicals (Lyche et al., 2015). Infants are more vulnerable than older humans to potentially harmful chemicals because they have immature metabolism systems and because some development processes are sensitive to the presence of potentially harmful chemicals (Darnerud et al., 2001). Children appear to be exposed to larger amounts of CPs than are adults via the diet (Iino et al., 2005). In biomonitoring studies, breast milk offers several advantages over other tissues. Breast milk is simple to collect and collection is non-invasive, and it allows the body burdens of reproductive age women, in utero exposure of fetuses, and exposure of infants through breast feeding to be estimated. High SCCP and MCCP concentrations have been found in breast milk collected in urban areas in China, indicating that the production and use of CPs may be important sources of CP exposure in urban areas (Xia et al., 2017). China is one of the largest and most populous countries. The rural population was $48 \%$ of the total population of China in 2011, but the incomes of people living in rural areas accounted for only $25 \%$ of the total incomes of people in China. This means there are significant differences in the lifestyles and dietary habits of people living in urban and rural areas in China. Breast milk produced by women living in urban and rural areas may contain different $\mathrm{CP}$ concentrations, and the sources of CPs found in breast milk produced by women living in urban and rural areas may be different. To understand the occurrence, congener profile, and sources of CPs in breast milk produced by women living in rural areas in China, the study described here was focused on SCCP and MCCP concentrations in breast milk in Chinese rural population.

A total of 1412 individual human breast milk samples were collected from rural areas in eight provinces across China in 2007 and from 16 provinces in 2011. The samples were pooled to give 24 samples, and 48 SCCP and MCCP formula congeners were determined in the pooled samples by comprehensive two-dimensional gas chromatography coupled to electron capture negative ionization high-resolution timeof-flight mass spectrometry (GC $\times$ GC-ECNI-HRTOFMS).

The aim of the study was to estimate background $\mathrm{CP}$ body burdens in the general population of rural areas in China. Daily CP intakes by infants were estimated, and the potential health risks posed to nursing infants by CPs in breast milk were assessed. Possible sources and pathways of CPs and associations between CP exposure and maternal characteristics were also evaluated.

\section{Materials and methods}

\subsection{Donor selection and sample collection}

Breast milk samples were collected from rural areas in eight Chinese provinces in 2007 and 16 Chinese provinces in 2011. The donor selection, sampling, and pooling protocols were based on the 'Guidelines for Developing a National Protocol' developed as part of the 'Fourth WHO-Coordinated Survey of Breast milk for Persistent Organic Pollutants in Cooperation with UNEP' (WHO, 2007). The breast milk samples were collected using a multistage random cluster sampling method. First, the provinces were divided into "northern" and "southern" groups depending on both their geographical locations and the dietary patterns of the residents of the provinces. Samples were collected from eight provinces in 2007 and 16 provinces in 2011, and the women samples were selected at random. The 16 provinces samples were collected from were Fujian, Guangdong, Guangxi, Hebei, Heilongjiang, Henan,
Hubei, Jiangxi, Jilin, Liaoning, Neimenggu, Ningxia, Qinghai, Shanghai, Shanxi, and Sichuan (see Fig. S1 in Supplementary material). $>50 \%$ of the total population of China live in these provinces. Two rural sites in each province were randomly selected in each province, then 30 breast milk donors were randomly selected at each rural site. Each donor was primiparous, and the donors were 17-39y old (mean $26 \mathrm{y}$ ) and all lived in areas in which occupational exposure did not occur. Each donor supplied her age, weight, residence record, and dietary habits before pregnancy. The donor's ages ranges and sample collection numbers in each province are detailed in Table S1. The characteristics of the donors in 2007 were described in previous publications in which studies of dioxin-like compounds and polybrominated diphenyl ethers in breast milk were described (Li et al., 2009; Zhang et al., 2011). At least $50 \mathrm{~mL}$ of milk was collected from each of 60 donors in two rural areas in each selected province. Each sample was collected directly into a pre-washed jar. A total of 452 samples were collected from eight provinces in 2007 and 960 samples were collected from 16 provinces in 2011. Each sample was stored at $-20^{\circ} \mathrm{C}$ until it was pooled and analyzed. The 60 individual samples from each province were pooled to give one sample, so there were eight pooled samples in 2007 and 16 pooled samples in 2011.

\subsection{Sample preparation}

Approximately $30 \mathrm{~mL}$ of a pooled sample was freeze-dried and then spiked with $2.5 \mathrm{ng}$ of ${ }^{13} \mathrm{C}_{10}$-labeled trans-chlordane. The sample was then extracted with a 1:1 mixture of dichloromethane and $n$-hexane using an ASE 350 extraction unit (Dionex, Sunnyvale, CA, USA). The extract was evaporated to dryness to allow the lipid content to be determined gravimetrically. The residue was then redissolved and the lipids removed by gel permeation chromatography, then the extract was cleaned by passing it through a multi-layered column. The cleaned extract was concentrated, solvent exchanged into cyclohexane, evaporated to $50 \mu \mathrm{L}$ in a vial containing $2.5 \mathrm{ng}$ of $\varepsilon$-hexachlorocyclohexane, and analyzed by GC $\times$ GC-ECNI-HRTOFMS. The sample extraction and cleanup procedures are described in detail in the Supplementary material.

\subsection{Instrumental analysis and quantification}

The sample extracts were analyzed by GC $\times$ GC-ECNI-HRTOFMS. The gas chromatograph (Agilent Technologies, Santa Clara, CA, USA) was fitted with a ZX2004 loop cryogenic modulator (Zoex Corporation, Houston, TX, USA) and was connected to a HRTOFMS instrument (Tofwerk, Thun, Switzerland). The first column was a DB-5MS column (30 m long, $0.25 \mathrm{~mm}$ i.d., $0.25 \mu \mathrm{m}$ film thickness; Agilent Technologies) and the second column was a BPX-50 column ( $1 \mathrm{~m}$ long, $0.1 \mathrm{~mm}$ i.d., 0.1 $\mu \mathrm{m}$ film thickness; SGE Analytical Science, Ringwood, Australia). A single aliquot of a sample was injected into the gas chromatograph to analyze 48 SCCP $\left(\mathrm{C}_{10-13} \mathrm{Cl}_{5-10}\right)$ and $\operatorname{MCCP}\left(\mathrm{C}_{14-17} \mathrm{Cl}_{5-10}\right)$ formula congeners. The procedures used to identify and quantify the CPs are described in a previous publication about the development of the GC $\times$ GC-ECNIHRTOFMS method (Xia et al., 2016).

\subsection{Quality assurance/quality control}

To ensure the validity of quantifications method, all glassware was heated to $450{ }^{\circ} \mathrm{C}$ before use to minimize the risk of contamination. Three replicate $\mathrm{CP}$-free cow milk samples spiked with a SCCP standard $(55.5 \% \mathrm{Cl}, 1 \mu \mathrm{g})$ and a MCCP standard ( $57 \% \mathrm{Cl}, 1 \mu \mathrm{g})$, were cleaned up and analyzed using the same method as was used for the breast milk samples. The mean SCCP and MCCP recoveries were $89 \%$ and $85 \%$, respectively. The samples were analyzed in batches of seven, and one procedural blank was included with each batch. The estimated method detection limits were $5.6 \mathrm{ng} \mathrm{g}^{-1} \mathrm{lw}$ for the SCCPs and $2.0 \mathrm{ng} \mathrm{g}^{-1} \mathrm{lw}$ for the MCCPs. The procedural blanks were extracted and analyzed in the same way as the samples. The SCCP concentrations in the blanks 
were less than one-tenth of the concentrations in the breast milk samples, and the MCCP concentrations in the blanks were below the method detection limit. The ${ }^{13} \mathrm{C}_{10}$-labeled trans-chlordane recoveries for the milk samples were $57 \%-119 \%$, and the mean was $92 \%$.

\section{Results and discussion}

\subsection{Concentrations of SCCP and MCCP in human breast milk}

The SCCP and MCCP concentrations in the 24 pooled samples are presented in Table 1. The SCCP and MCCP concentrations were higher than the method detection limits in all the samples. The median total SCCP and MCCP concentrations were 303 and $35.7 \mathrm{ng} \mathrm{g}^{-1} \mathrm{lw}$, respectively, in the 2007 samples, and 360 and $45.4 \mathrm{ng} \mathrm{g}^{-1} \mathrm{lw}$, respectively, in the 2011 samples. Both the SCCP and MCCP concentrations in samples from different locations were significantly different, as shown in Fig. 1 . The SCCP concentrations varied by about three orders of magnitude between different provinces in both the 2007 samples and the 2011 samples. In the 2007 samples, the lowest SCCP concentration (68.0 $\mathrm{ng} \mathrm{g}^{-1} \mathrm{lw}$ ) was found in the sample from Ningxia Province and the highest concentration (1580 $\mathrm{ng} \mathrm{g}^{-1} \mathrm{lw}$ ) was found in the sample from Hebei Province. In the 2011 samples, the lowest SCCP concentration (65.6 ng g ${ }^{-1} \mathrm{lw}$ ) was found in the sample from Qinghai Province and the highest concentration ( $2310 \mathrm{ng} \mathrm{g}^{-1} \mathrm{lw}$ ) was found in the sample from Hebei Province. The lowest MCCP concentration in the 2007 samples (9.05 $\mathrm{ng} \mathrm{g}^{-1} \mathrm{lw}$ ) was found in the sample from Heilongjiang Province, and the lowest concentration in the 2011 samples (9.51 $\mathrm{ng} \mathrm{g}^{-1} \mathrm{lw}$ ) was found in the sample from Guangxi Province. The highest MCCP concentrations in both 2007 and 2011 were found in the samples from Hebei Province.

The SCCP concentrations were much higher than the MCCP concentrations, and the SCCP concentrations contributed up to $90 \%$ of the total CP concentrations. The SCCP and MCCP concentrations were lower in the 2007 samples than in the 2011 samples. For the eight provinces from which samples were collected in both sampling years, the median SCCP concentration increased by 53\% between 2007 and 2011, from $303 \mathrm{ng} \mathrm{g}^{-1} \mathrm{lw}$ in 2007 to $654 \mathrm{ng} \mathrm{g}^{-1} \mathrm{lw}$ in 2011. The median MCCP concentration increased by 55\% between 2007 and 2011, from $35.7 \mathrm{ng} \mathrm{g}^{-1}$ lw in 2007 to $79 \mathrm{ng} \mathrm{g}^{-1}$ lw in 2011.

Detecting SCCPs and MCCPs in the samples demonstrated that both SCCPs and MCCPs can accumulate to some extent in human breast milk. Scarcer data on SCCP and MCCP concentrations in human breast milk around the world with which to compare our results are available. The $\mathrm{CP}$ concentrations in samples from some provinces (e.g., Neimenggu

Table 1

Short-chain chlorinated paraffin (SCCP) and medium-chain chlorinated paraffin (MCCP) concentrations ( $\mathrm{ng} \mathrm{g}^{-1}$ lipid weight) in the 24 pooled human breast milk samples (from eight Chinese provinces in 2007 and 16 Chinese provinces in 2011).

\begin{tabular}{|c|c|c|c|c|c|c|}
\hline & \multicolumn{3}{|l|}{2007} & \multicolumn{3}{|l|}{2011} \\
\hline & $\begin{array}{l}\text { Percent } \\
\text { lipid (\%) }\end{array}$ & $\sum \mathrm{SCCPS}$ & $\sum \mathrm{MCCPS}$ & $\begin{array}{l}\text { Percent } \\
\text { lipid (\%) }\end{array}$ & $\sum \mathrm{SCCPS}$ & $\sum \mathrm{MCCPS}$ \\
\hline Heilongjiang & 3.8 & 166 & 9.05 & 3.7 & 217 & 15.3 \\
\hline Hebei & 3.2 & 1580 & 139 & 3.0 & 2310 & 146 \\
\hline Ningxia & 4.2 & 68.0 & 13.5 & 4.1 & 147 & 29.0 \\
\hline Henan & 3.0 & 694 & 72.3 & 3.2 & 975 & 80.8 \\
\hline Shanxi & 3.7 & 269 & 30.9 & 3.7 & 784 & 68.1 \\
\hline Shanghai & 3.6 & 1190 & 85.1 & 3.6 & 2130 & 100 \\
\hline Hubei & 3.2 & 311 & 40.5 & 3.1 & 524 & 113 \\
\hline Fujian & 3.7 & 296 & 15.5 & 4.0 & 503 & 55.4 \\
\hline Jilin & - & - & - & 3.1 & 143 & 35.4 \\
\hline Liaoning & - & - & - & 3.5 & 649 & 65.1 \\
\hline Neimenggu & - & - & - & 4.0 & 75.4 & 15.1 \\
\hline Qinghai & - & - & - & 4.2 & 65.6 & 18.1 \\
\hline Sichuan & - & - & - & 3.0 & 175 & 12.0 \\
\hline Jiangxi & - & - & - & 3.8 & 840 & 58.0 \\
\hline Guangxi & - & - & - & 4.1 & 89.8 & 9.51 \\
\hline Guangdong & - & - & - & 4.1 & 77.6 & 21.6 \\
\hline
\end{tabular}

and Qinghai) were in the same order of magnitude as concentrations that have been found in human breast milk from Quebec in Canada (11.0-17.0 $\mathrm{ng} \mathrm{g}^{-1} \mathrm{lw}$ for SCCPs) (Tomy, 1997). The SCCP and MCCP concentrations in the samples from Hebei Province and Henan Province were significantly higher than the concentrations found in human breast milk samples from Lancaster in the UK (49-820 $\mathrm{ng} \mathrm{g}^{-1} \mathrm{lw}$ for SCCPs and 0.81-14.0 $\mathrm{ng} \mathrm{g}^{-1} \mathrm{lw}$ for MCCPs) (Thomas et al., 2006). The SCCP and MCCP concentrations in our samples from rural areas were lower than the SCCP and MCCP concentrations that we previously found in breast milk from urban areas in China (681 $\mathrm{ng} \mathrm{g}^{-1} \mathrm{lw}$ for SCCPs and $60.4 \mathrm{ng} \mathrm{g}^{-1}$ lw for MCCPs) (Xia et al., 2017). The higher CP concentrations in breast milk from urban areas may have been related to larger amounts of CPs being produced and used in more industrialized urban areas than rural areas. There are significant differences in the lifestyles and dietary habits of people living in urban and rural areas, and these will affect exposure to $\mathrm{CPs}$ and the $\mathrm{CP}$ concentrations in the milk samples we analyzed. High CP concentrations have been found in urban indoor environments, in which humans are exposed to $\mathrm{CPs}$ released from $\mathrm{CP}$-containing materials. Moreover, larger amounts of foods of animal origin may be consumed by people living in urban areas than by people living in rural areas. Foods of animal origin are also important sources of CPs to humans. Overall, the CP concentrations may have been lower in the samples from rural areas than in the samples from urban areas because of the absence of industrial activities in rural areas. Long-range atmospheric transport of CPs may be the main source of CPs in rural areas.

\subsection{SCCP and MCCP composition in human breast milk}

The SCCP and MCCP composition profiles in all 24 pooled samples are shown in Fig. 2. The SCCP and MCCP congener patterns in the samples from different provinces were not markedly different. The SCCP composition profiles in the samples from the 16 different provinces were generally similar, with the $C_{10}$ and $C_{11}$ congener groups being dominant and contributing, on average, $51 \%$ and $28 \%$, respectively, of the total SCCP concentration. The shorter-chain $\mathrm{C}_{10}$-CPs were more abundant in the samples from rural areas than in the samples from urban areas (contributing 47\% of the total SCCP concentrations) (Xia et al., 2017). CPs with shorter carbon chains are more favorably transported long distances in the atmosphere than are CPs with longer carbon chains. The results suggest that long-range atmospheric transport of CPs may be an important source of CPs in rural areas in China. The $\mathrm{Cl}_{6}$ and $\mathrm{Cl}_{7}$ congener groups were the most abundant SCCPs in all the samples. The most abundant SCCP homolog groups were $\mathrm{C}_{10} \mathrm{H}_{16} \mathrm{Cl}_{6}$ and $\mathrm{C}_{10} \mathrm{H}_{15} \mathrm{Cl}_{7}$. The most abundant MCCP group was the $\mathrm{C}_{14}$ group, which contributed, on average, $82 \%$ of the total MCCP concentration. The $\mathrm{Cl}_{7}$ and $\mathrm{Cl}_{8}$ congener groups were the most abundant MCCPs in all the samples. The most abundant MCCP homolog groups in the samples from most of the provinces were $\mathrm{C}_{14} \mathrm{H}_{23} \mathrm{Cl}_{7}$ and $\mathrm{C}_{14} \mathrm{H}_{22} \mathrm{Cl}_{8}$.

The $\mathrm{CP}$ composition profiles in our samples were similar to profiles that have been found in indoor air and surface films on glass windows in Beijing, China, in which $C_{10}$ and $C_{11}$ were found to be the most abundant components (Gao et al., 2016). Similar congener patterns have also been found in indoor air and dust in Stockholm, Sweden and in London, UK (Fridén et al., 2011; Peters et al., 2000). We therefore speculate that CPs in indoor air and dust could be an important source of CPs to the general population of China. CPs can be released from materials that contain CPs in the indoor environment. Further studies and more information will be required to determine the contribution inhaled air and dust make to total exposure of the general population to CPs.

\subsection{Exposure pathways and associations between CP concentrations and maternal characteristics}

It is essential to understand potential exposure pathways when conducting comprehensive human health risk assessments. There are 


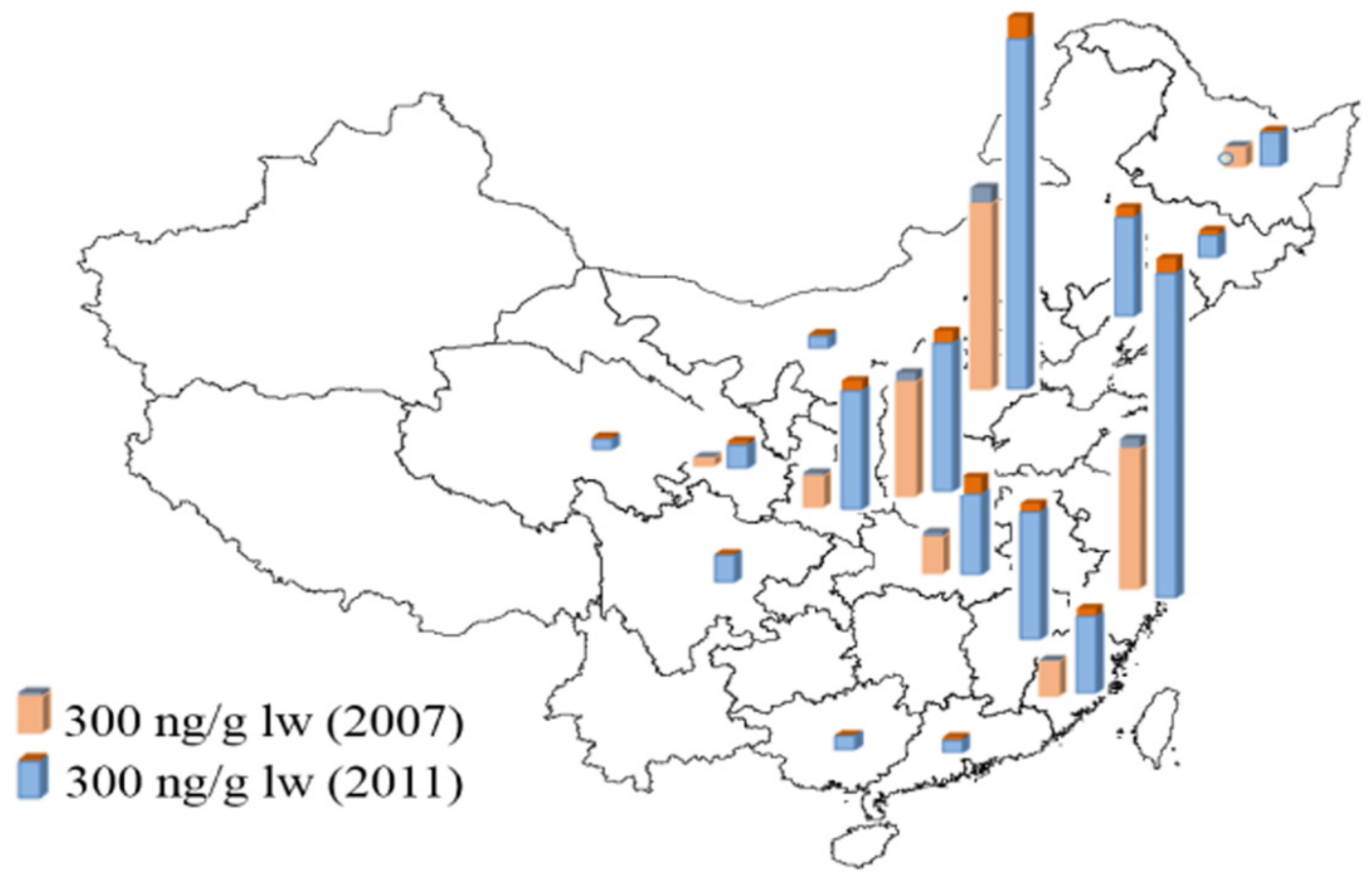

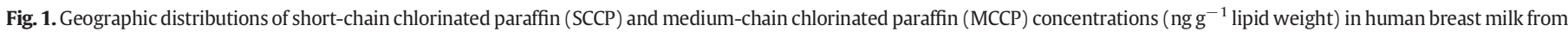
different provinces in rural China. (Yellow color was indicated for SCCP and blue for MCCP in 2007 samples; blue was indicated for SCCP and red for MCCP in 2011 samples).

numerous sources of information on $\mathrm{CP}$ concentrations in environmental matrices, but the specific pathways through which the general human population is exposed to CPs are still unclear. Various pathways through which humans could be exposed to CPs have been proposed. It has been suggested that food is an important source of CPs to humans.
Market basket surveys have been performed in Japan, and SCCPs were found in 11 food product categories, including apples, bread, green beans, ground beef, and milk (Iino et al., 2005). Harada et al. (2011) found that dietary exposure of Beijing residents to SCCPs increased by two orders of magnitude between 1993 and 2009, to a geometric
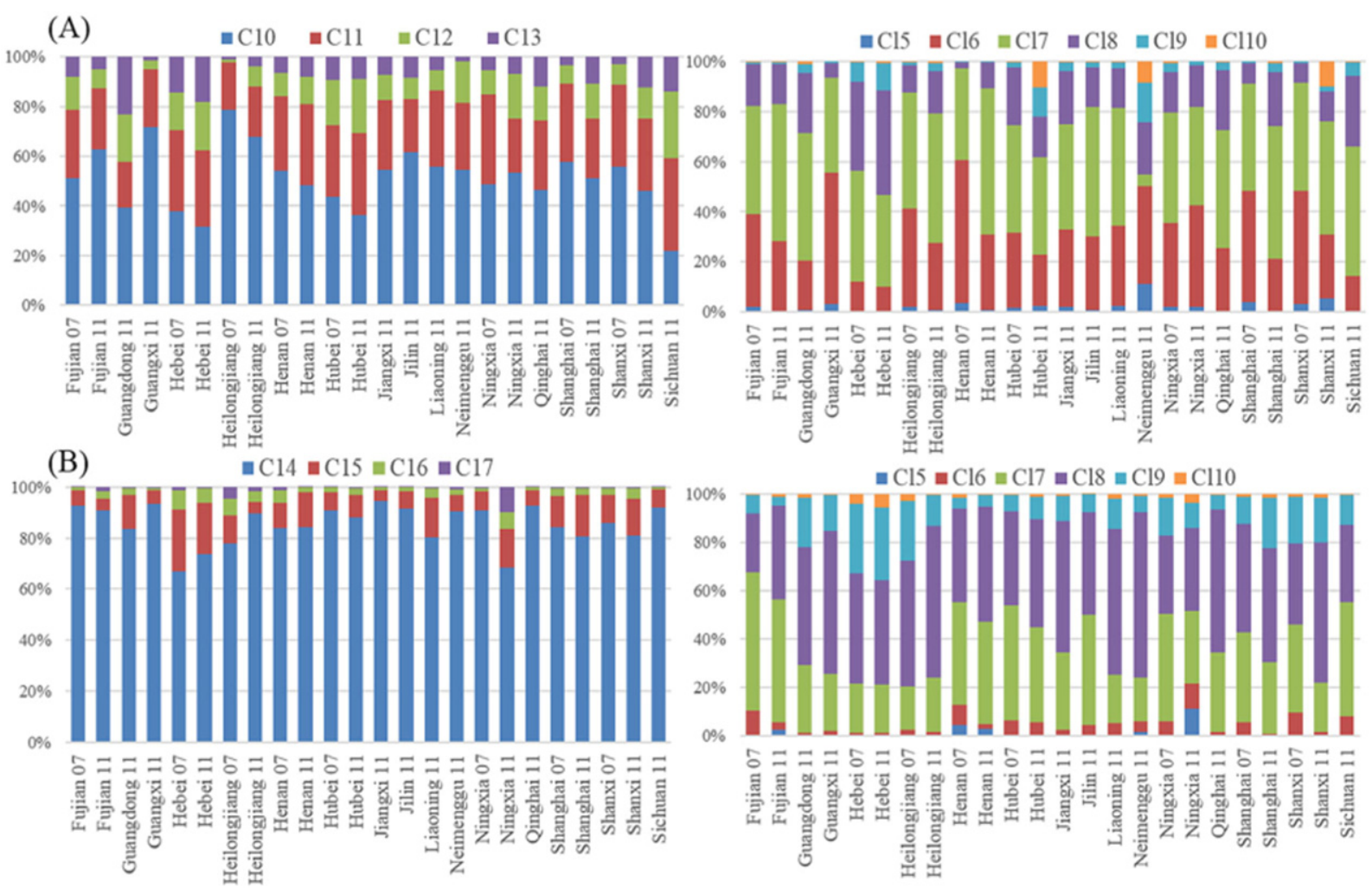

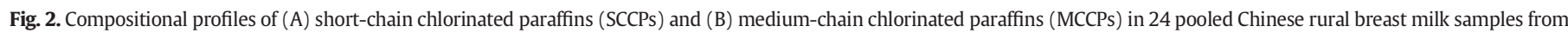
eight provinces in 2007 and 16 provinces in 2011. 
mean exposure rate of $620 \mathrm{ng} \mathrm{kg}^{-1} \mathrm{~d}^{-1}$ in 2009. It has been estimated that the dietary intakes of SCCPs in cooking oil by Chinese people range from 0.78 to $38.0 \mu \mathrm{g} \mathrm{d}^{-1}$ (Cao et al., 2015). Meanwhile, it has been predicted using a human exposure model that the consumption of fish could contribute high proportions ( $80 \%-100 \%$ ) of SCCP intakes in Nordic countries (Krogseth et al., 2013). Dietary information was collected from all of the donors of samples in our study to allow us to attempt to determine whether food could be an important source of CPs in breast milk in China. The major foods consumed by the donors included dairy products, eggs, fish, pork and beef, poultry, and vegetables. A significant positive correlation was found between the SCCP and MCCP concentrations in 2011 human breast milk and the consumption of fish using Pearson correlation analysis $(r=0.676, p<0.01$, SCCPs; $r=$ $0.728, p<0.01$, MCCPs). It is likely that Chinese people may be exposed to CPs through using consumer products containing CPs and/or through consuming foods contaminated with CPs. However, no definitive conclusion could be drawn because pooled samples were analyzed. Chinese people may also be exposed to CPs through inhaling indoor air and dust. It has been suggested that inhalation and the ingestion of dust could be the dominant routes through which adults and toddlers are exposed to CPs in the indoor environment in Sweden (Fridén et al., 2011). The 95th percentile of the total SCCP and MCCP exposure rate through inhalation and dust ingestion in Sweden has been estimated to be $56.7 \mathrm{ng} \mathrm{kg}^{-1} \mathrm{~d}^{-1}$ for adults and $490 \mathrm{ng} \mathrm{kg}{ }^{-1} \mathrm{~d}^{-1}$ for toddlers (Fridén et al., 2011). Meanwhile, high SCCP concentrations have been found in indoor air (0.06-1.35 $\left.\mathrm{g} \mathrm{m}^{-3}\right)$ and organic films on windows (0.34$54.0 \mu \mathrm{g} \mathrm{m}^{-2}$ ) in Beijing, indicating that humans can be exposed to relatively large amounts of CPs in indoor environments (Gao et al., 2016). Such exposure levels could lead to $\mathrm{CP}$ concentrations in breast milk being high. A clear and comprehensive study of $\mathrm{CP}$ sources and exposure pathways requires $\mathrm{CP}$ concentrations in food, indoor air and dust to be measured to allow the specific pathways through which the general population of China are exposed to CPs to be identified.

Correlations between the $\mathrm{CP}$ concentrations and maternal age and maternal weight were investigated. The mean maternal age was $25.8 \mathrm{y}$, and the mean maternal weight was $60.4 \mathrm{~kg}$. The SCCP and MCCP concentrations did not correlate with these parameters $(p>$ 0.05). Positive correlations have recently been found between the concentrations of some POPs (e.g., organochlorine pesticides and polybrominated diphenyl ethers) in human milk and maternal age (Chao et al., 2010; Man et al., 2014). The lack of a relationship between maternal age and $\mathrm{CP}$ concentration in our study was probably caused by pooled samples being analyzed and the large maternal age range. Moreover, the production and use of CPs is currently not restricted in China, and the annual production of CPs increased by a factor of five between 2004 and 2009 and increased further by 2015 (Wei et al., 2016). This means CP concentrations in human tissues will continually increase, and this could conceal correlations between maternal age and the $\mathrm{CP}$ concentration.

\subsection{Dietary intakes of CPs by nursing infants via breast milk}

Persistent organic pollutants are directly transferred from the mother to the nursing infant in breast milk. Understanding the total exposure of infants to CPs requires the dietary intakes of CPs by the infants in breast milk to be assessed. We assumed that breast milk is the only food source for a 1 month old nursing infant, and calculated the total $\left(\sum\right.$ ) SCCP and $\sum$ MCCP intakes of an infant via breast milk using Eq. (1),

$\mathrm{EDI}_{\sum \mathrm{SCCPs} / \mathrm{MCCPs}}=\mathrm{C}_{\text {breast milk }} \times \mathrm{M} \times \mathrm{R} \times \Phi / \mathrm{BW}$,

where EDI is the estimated dietary intake of $\sum$ SCCPs or $\sum$ MCCPs (ng kg-1 $\mathrm{d}^{-1}$ ), $\mathrm{C}_{\text {breast milk }}$ is the SCCP or MCCP concentration in human breast milk ( $\mathrm{ng} \mathrm{g}^{-1} \mathrm{lw}$ ), $\mathrm{M}$ is the daily lipid intake in breast milk $\left(\mathrm{g} \mathrm{d}^{-1}\right), \mathrm{R}$ is the lipid content (in percent) of the milk samples that were analyzed, $\Phi$ is the $\mathrm{CP}$ absorption efficiency percent of an infant, and BW is the body weight of an infant. The $\Phi$ value was assumed to be $100 \%$, as specified in US Environmental Protection Agency guidelines (U.S. EPA, 2002). The daily lipid intake in breast milk was calculated using an infant weight of $6 \mathrm{~kg}$ and an average milk intake of $750 \mathrm{~mL} \mathrm{~d}^{-1}$, taken from the "Chinese Dietary Reference Intakes Handbook" (CNS, 2013). The median lipid content of the milk samples analyzed was $3.6 \mathrm{~g}$ lipid per $100 \mathrm{~mL}$ of breast milk for the 2007 samples and $3.7 \mathrm{~g}$ lipid per $100 \mathrm{~mL}$ of breast milk for the 2011 samples. The

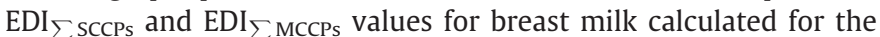
SCCP and MCCP concentrations (using the 5th, 50th, and 95th percentiles of the total concentrations determined from our breast milk data) for the 2007 and 2011 samples are shown in Table 2. The median $\mathrm{EDI}_{\sum \mathrm{SCCPs}}$ values for human milk were $1310 \mathrm{ng} \mathrm{kg}^{-1} \mathrm{~d}^{-1}$ (range $357-6320 \mathrm{ng} \mathrm{kg}^{-1} \mathrm{~d}^{-1}$ ) for the 2007 samples and $1520 \mathrm{ng} \mathrm{kg}^{-1} \mathrm{~d}^{-1}$ (range 344-8650 $\mathrm{ng} \mathrm{kg}^{-1} \mathrm{~d}^{-1}$ ) for the 2011 samples. The median EDI $\sum$ MCCPs values for human milk were $152 \mathrm{ng} \mathrm{kg}^{-1} \mathrm{~d}^{-1}$ (range 43.0-554 $\mathrm{ng} \mathrm{kg}^{-1} \mathrm{~d}^{-1}$ ) for the 2007 samples and $212 \mathrm{ng} \mathrm{kg}^{-1} \mathrm{~d}^{-1}$ (range 43.1-450 $\mathrm{ng} \mathrm{kg}^{-1} \mathrm{~d}^{-1}$ ) for the 2011 samples.

This is the first time the dietary intakes of CPs by nursing infants in breast milk have been investigated. lino et al. (2005) determined SCCP concentrations in 11 food product categories in Japan and estimated that the 95th percentile of the total daily intake for a 1 year old female was $680 \mathrm{ng} \mathrm{kg}^{-1} \mathrm{~d}^{-1}$. The EDI is an estimated value and will vary daily as the concentration of the pollutant of interest in the milk varies. The concentration of a chemical of interest in breast milk can vary during a lactation even when the concentration is expressed on a lipid weight basis. Our results indicate that continuous monitoring studies of CPs in Chinese human breast milk samples are required.

\subsection{Assessment of the health risks posed by CPs to infants}

Limited toxicity data are available for CPs, and no health-based guideline values have been established to allow the health risks posed to infants by exposure to CPs to be assessed. We estimated the health risks posed by SCCPs and MCCPs to infants using the margin of exposure (MOE), and we compared the MOE with uncertainty factors (EC, 1999; U.S. EPA, 2002). The MOE is defined as shown in Eq. (2),

$\mathrm{MOE}=\mathrm{NOAEL} / \mathrm{EDI}_{\sum \mathrm{SCCPs} / \mathrm{MCCP}}$,

where NOAEL is the no observed adverse effect level for human health and EDI is the daily SCCP intake of an infant via breast milk. NOAELs for tubular pigmentation effects of $100 \mathrm{mg} \mathrm{kg}^{-1} \mathrm{~d}^{-1}$ and $23 \mathrm{mg} \mathrm{kg}^{-1} \mathrm{~d}^{-1}$ were used for SCCPs and MCCPs, respectively, determined from toxicity test results for mammals (ECB, 2000; ECB, 2007). A total uncertainty factor of 1000 was applied. This included a factor of 10 for a study period of $<1 \mathrm{y}$, a factor of 10 for interspecies differences, and a factor of 10 for individual differences (Pieters et al., 1998).

A MOE larger than the uncertainty factor of 1000 was taken to indicate that no significant health risks were posed to infants. From the SCCPs EDI for breast milk, the 95th percentile intakes for a 1 month old infant in 2007 and 2011 were estimated to be 6320 and $8650 \mathrm{ng} \mathrm{kg}^{-1} \mathrm{~d}^{-1}$, respectively. Meanwhile, From the MCCPs EDI for

Table 2

Estimated daily short-chain chlorinated paraffins (SCCPs) and medium-chain chlorinated paraffins (MCCPs) intakes ( $\mathrm{ng} \mathrm{kg}^{-1} \mathrm{~d}^{-1}$ ) by Chinese infants (given as percentiles).

\begin{tabular}{llll}
\hline & 5th percentile & 50th percentile & 95th percentile \\
\hline 2007 & & & \\
$\sum$ SCCPs & 357 & 1310 & 6320 \\
$\sum$ MCCPs & 43.0 & 152 & 554 \\
2011 & & & 8650 \\
$\sum$ SCCPs & 344 & 1520 & 450 \\
$\sum$ MCCPs & 45.1 & 212 & \\
\hline
\end{tabular}


breast milk, the 95th percentile intakes for a 1 month old infant in 2007 and 2011 were estimated to be 554 and $450 \mathrm{ng} \mathrm{kg}^{-1} \mathrm{~d}^{-1}$, respectively. These values were applied to the tubular pigmentation endpoint. The MOEs $\left(1.4 \times 10^{5}\right.$ for SCCPs and $5.1 \times 10^{5}$ for MCCPs) for the toxicity endpoints were calculated to be larger than the uncertainty factors for all of the 2011 samples. This indicates that there were no appreciable health risks posed to infants by SCCPs and MCCPs in breast milk. It should be noted that the SCCPs MOEs in the Hebei Province sample collected in 2011 was 10,400 (i.e., close to the uncertainty factor of 1000), suggesting that CPs in breast milk may pose risks to infants in this province. Therefore, although total dietary SCCPs and MCCPs intakes currently pose no risks to infants in China, continuous risk assessments will be required, and the production and use of CPs will need to be controlled to avoid CP concentrations in Chinese breast milk continuing to increase.

Both SCCPs and MCCPs are on the EU endocrine disruptor candidates list. It has been found that MCCPs in breast milk pose risks to nursing infants because of hemorrhaging related to low vitamin K concentrations in the milk and the blood plasma (Lassen et al., 2014). SCCPs and MCCPs have similar physicochemical properties and toxicity profiles, so SCCPs in breast milk may also cause toxic effects in nursing infants (ECHA, 2008). A maternal dose NOAEL of $47 \mathrm{mg} \mathrm{kg}^{-1} \mathrm{~d}^{-1}$ has been determined for effects in infants through exposure to CPs in breast milk, so the $\mathrm{CP}$ concentrations we found in our milk samples would not have caused adverse health effects in the infants consuming the milk. However, it should be noted that our results raise concerns about the potential adverse effects CPs could cause in infants. Breast milk is a good source of nutrition, providing essential nutrients (including fats, carbohydrates, and proteins) to infants and being important to the development of a competent immune system (Horta et al., 2007). However, it would be prudent to perform further investigations to clarify the risks posed to infants by CPs in breast milk. Breastfeeding mothers should be encouraged and supported because of the beneficial effects of breastfeeding, but scientific studies are required to characterize and measure contaminants in breast milk so that protective measures may be provided, if necessary, to avoid potential harmful effects contaminants may have on mothers or newborn infants.

\section{Conclusions}

This was the first study in which SCCP and MCCP concentrations in human breast milk from people living in rural areas in China have been determined. The SCCP and MCCP concentrations in breast milk from different provinces varied by more than two orders of magnitude. The general population of China is probably exposed to CPs from multiple sources and through various pathways. Daily SCCP intakes by Chinese infants were estimated, and the health risks posed to infants by CPs were assessed. The results suggested that current SCCP concentrations pose no risks to infants. However, SCCP and MCCP concentrations in the tissues of the general population of China are increasing, so $\mathrm{CP}$ concentrations in human milk need to be continually monitored to allow both environmental pollution by CPs and the health risks posed by CPs to the Chinese population to be accurately evaluated in the future. A more comprehensive exposure study will require $\mathrm{CP}$ concentrations in food, indoor air and dust to be determined to allow the specific pathways through which humans are exposed to CPs to be identified.

\section{Acknowledgments}

This study was funded by the National 973 Program [grant no. 2015CB453100], the National Natural Science Foundation of China [grant nos. 21377140, 21361140359, 21577152, 21537001, and 21321004], and the Strategic Priority Research Program of the Chinese Academy of Sciences [grant nos. XDB14010100 and XDB14020102].

\section{Appendix A. Supplementary data}

Supplementary data to this article can be found online at http://dx. doi.org/10.1016/j.envint.2017.03.013.

\section{References}

Bayen, S., Obbard, J.P., Thomas, G.O., 2006. Chlorinated paraffins: a review of analysis and environmental occurrence. Environ. Int. 32, 915-929.

Cao, Y., Harada, K.H., Liu, W., Yan, J., Zhao, C., Niisoe, T., Adachi, A., Fujii, Y., Nouda, C., Takasuga, T., Koizumi, A., 2015. Short-chain chlorinated paraffins in cooking oil and related products from China. Chemosphere 138, 104-111.

Chao, H.A., Chen, S.C., Chang, C.M., Koh, T.W., Chang, C.G.P., Ouyang, E., 2010. Concentrations of polybrominated diphenyl ethers in breast milk correlated to maternal age, education level, and occupational exposure. J. Hazard. Mater. 175, 492-500.

CNS, Chinese Nutrition Society, 2013. Chinese Dietary Reference Intakes Handbook. Standards Press of China, Beijing.

Cooley, H.M., Fisk, A.T., Wiens, S.C., Tomy, G.T., Evans, R.E., Muir, D.C.G., 2001. Examination of the behavior and liver and thyroid histology of juvenile rainbow trout (Oncorhynchus mykiss) exposed to high dietary concentrations of C-10-, C-11-, C-12- and C-14polychlorinated N-alkanes. Aquat. Toxicol. 54, 81-99.

Darnerud, P.O., Eriksen, G.S., Johannesson, T., Larsen, P.B., Viluksela, M., 2001 Polybrominated diphenyl ethers: occurrence, dietary exposure, and toxicology. Environ. Health Perspect. 109, 49-68.

EC, European Commission, 1999. European Union Risk Assessment Report Alkanes, C10 13, Chloro, CAS-No.: 85535-84-8, EINECS-No.: 287-476-5, Risk Assessment. European Chemical Bureau, Luxembourg.

ECB, European Chemicals Bureau, 2000. European Union Risk Assessment Report, Alkanes, $\mathrm{C}_{10-13}$, Chloro. European Commission, Devon, England.

ECB, European Chemicals Bureau, 2007. European Union Risk Assessment Report, Alkanes, $\mathrm{C}_{14-17}$, Chloro. European Commission, Devon, England.

ECHA, 2008. SVHC Support document for identification of Alkanes, C10-13, chloro, as a substance of very high concern. Adopted on 8 October 2008. European Chemicals Agency.

Fridén, U.E., McLachlan, M.S., Berger, U., 2011. Chlorinated paraffins in indoor air and dust: concentrations, congener patterns, and human exposure. Environ. Int. 37 1169-1174.

Gao, W., Wu, J., Wang, Y.W., Jiang, G.B., 2016. Distribution and congener profiles of shortchain chlorinated paraffins in indoor/outdoor glass window surface films and their film-air partitioning in Beijing, China. Chemosphere 144, 1327-1333.

Harada, K.H., Takasuga, T., Hitomi, T., Wang, P.Y., Matsukami, H., Koizumi, A., 2011. Dietary exposure to short-chain chlorinated paraffins has increased in Beijing, China. Environ. Sci. Technol. 45, 7019-7027.

Horta, B.L., Bahl, R., Martines, J.C., Victora, C.G., 2007. Evidence of long-term effects of breast-feeding. Systematic Reviews and Meta-analyses. World Health Organization, Geneva.

Houde, M., Muir, D.C.G., Tomy, G.T., Whittle, D.M., Teixeira, C., Moore, S., 2008. Bioaccumulation and trophic magnification of short- and medium-chain chlorinated paraffins in food webs from Lake Ontario and Lake Michigan. Environ. Sci. Technol. 42 3893-3899.

Iino, F., Takasuga, T., Senthilkumar, K., Nakamura, N., Nakanishi, J., 2005. Risk assessment of short-chain chlorinated paraffins in Japan based on the first market basket study and species sensitivity distributions. Environ. Sci. Technol. 39, 859-866.

Krogseth, I.S., Breivik, K., Arnot, J.A., Wania, F., Borgen, A.R., Schlabach, M., 2013. Evaluating the environmental fate of short-chain chlorinated paraffins (SCCPs) in the Nordic environment using a dynamic multimedia model. Environ. Sci. Process. Impacts 15 2240-2251.

Lassen, C., Sørensen, G., Crookes, M., Christensen, F., Jeppesen, C.N., Mikkelsen, S.H., Nielsen, J.M., 2014. Survey of Short-chain and Medium Chlorinated Paraffins. Part of the LOUS-review. Environmental Project No. 1614. Danish Environmental Protection Agency, Copenhagen.

Li, J.G., Zhang, L., Wu, Y.N., Liu, Y.P., Zhou, P.P., Wen, S., Liu, J.Y., Zhao, Y.F., Li, X.L., 2009. A national survey of polychlorinated dioxins, furans (PCDD/Fs) and dioxin-like polychlorinated biphenyls (dl-PCBs) in human milk in China. Chemosphere 75, 1236-1242.

Li, H.J., Fu, J.J., Zhang, A.Q., Zhang, Q.H., Wang, Y.W., 2016. Occurrence, bioaccumulation and long-range transport of short-chain chlorinated paraffins on the Fildes Peninsula at King George Island, Antarctica. Environ. Int. 94, 408-414.

Luo, X.J., Sun, Y.X., Wu, J.P., Chen, S.J., Mai, B.X., 2015. Short-chain chlorinated paraffins in terrestrial bird species inhabiting an e-waste recycling site in South China. Environ. Pollut. 198, 41-46.

Lyche, J.L., Rosseland, C., Berge, G., Polder, A., 2015. Human health risk associated with brominated flame-retardants (BFRs). Environ. Int. 74, 170-180.

Man, Y.B., Chan, J.K.Y., Wang, H.S., Wu, S.C., Wong, M.H., 2014. DDTs in mothers' milk, placenta and hair, and health risk assessment for infants at two coastal and inland cities in China. Environ. Int. 65, 73-82.

van Mourik, L.M., Leonards, P.E.G., Gaus, C., de Boer, J., 2015. Recent developments in capabilities for analysing chlorinated paraffins in environmental matrices: a review. Chemosphere 136, 259-272.

Persistent Organic Pollutants Review Committee, 2009. Supporting Document for the Risk Profile on Short-chained Chlorinated Paraffins. Stockholm Convention on Persistent Organic Pollutants, Geneva. 
Peters, A.J., Tomy, G.T., Jones, K.C., Coleman, P., Stern, G.A., 2000. Occurrence of $C_{10}-C_{13}$ polychlorinated $n$-alkanes in the atmosphere of the United Kingdom. Atmos. Environ. 34, 3085-3090.

Pieters, M.N., Kramer, H.J., Slob, W., 1998. Evaluation of the uncertainty factor for subchronic-to-chronic extrapolation: statistical analysis of toxicity data. Regul. Toxicol. Pharmacol. 27, 108-111.

Sverko, E., Tomy, G.T., Marvin, C.H., Muir, D.C., 2012. Improving the quality of environmental measurements on short chain chlorinated paraffins to support global regulatory efforts. Environ. Sci. Technol. 46, 4697-4698.

Thomas, G.O., Farrar, D., Braekevelt, E., Stern, G., Kalantzi, O.I., Martin, F.L., Jones, K.C. 2006. Short and medium chain length chlorinated paraffins in UK human milk fat. Environ. Int. 32, 34-40.

Tomy, G.T., 1997. The Mass Spectrometric Characterization of Polychlorinated $N$-alkane and the Methodology for Their Analysis in the Environment. University of Manitoba, Winnipeg.

Tomy, G.T., Fisk, A.T., Westmore, J.B., Muir, D.C., 1998. Environmental chemistry and toxicology of polychlorinated $N$-alkanes. Rev. Environ. Contam. Toxicol. 158, 53-128.

U.S. EPA, United States Environmental Protection Agency, 2002. A Review of the Reference Dose and Reference Concentration Processes (EPA/630/P-02/002F).

Wei, G.L., Liang, X.L., Li, D.Q., Zhuo, M.N., Zhang, S.Y., Huang, Q.X., Liao, Y.S., Xie, Z.Y., Guo T.L., Yuan, Z.J., 2016. Occurrence, fate and ecological risk of chlorinated paraffins in Asia: a review. Environ. Int. 92-93, 373-387.
WHO, World Health Organization, 2007. Fourth WHO-coordinated Survey of Human Milk for Persistent Organic Pollutants in Cooperation with UNEP. Guidelines for Developing a National Protocol.

Xia, D., Gao, L.R., Zheng, M.H., Tian, Q.C., Huang, H.T., Qiao, L., 2016. A novel method for profiling and quantifying short- and medium chain chlorinated paraffins in environmental samples using comprehensive two-dimensional gas chromatography - electron capture negative ionization high-resolution time-of-flight mass spectrometry. Environ. Sci. Technol. 50, 7601-7609.

Xia, D., Gao, L.R., Zheng, M.H., Li, J.G., Zhang, L., Wu, Y.N., Tian, Q.C., Huang, H.T., Qiao, L., 2017. Human exposure to short- and medium-chain chlorinated paraffins via mothers' milk in Chinese urban population. Environ. Sci. Technol. 51, 608-615.

Zeng, L.X., Wang, T., Wang, P., Liu, Q., Han, S.L., Yuan, B., Zhu, N.L., Wang, Y.W., Jiang, G.B., 2011. Distribution and trophic transfer of short-chain chlorinated paraffins in an aquatic ecosystem receiving effluents from a sewage treatment plant. Environ. Sci. Technol. 45, 5529-5535.

Zhang, L., Li, J.G., Zhao, Y.F., Li, X.W., Yang, X., Wen, S., Cai, Z.W., Wu, Y.N., 2011. A national survey of polybrominated diphenyl ethers (PBDEs) and indicator polychlorinated biphenyls (PCBs) in Chinese mothers' milk. Chemosphere 84, 625-633.

Zhou, Y.H., Asplund, L., Yin, G., Athanassiadis, I., Wideqvist, U., Bignert, A., Qiu, Y.L. Zhu, Z.L., Zhao, J.F., Bergman, A., 2016. Extensive organohalogen contamination in wildlife from a site in the Yangtze River Delta. Sci. Total Environ. 554-555, 320-328. 